\title{
Testing the mediating role of teachers' self-efficacy beliefs in the relationship between sources of efficacy information and students achievement
}

\author{
Fatemeh Shaterian Mohamadi • Hassan Asadzadeh
}

Received: 8 January 2011/Revised: 12 September 2011/Accepted: 15 December 2011/Published online: 28 December 2011

(C) The Author(s) 2011. This article is published with open access at Springerlink.com

\begin{abstract}
The purpose of this study is to test the mediating role of teachers' self-efficacy beliefs in the relationship between sources of efficacy information and students achievement. For achieving this aim, this study suggests two alternative models, tested by Structural equation modeling (SEM) technique. In the first model, sources of efficacy information and teachers' sense of self-efficacy independently influenced student achievement. In second model, we examined a dependent 2-factor model, consisting of: (a) antecedent variable: sources of efficacy information, (b) mediator variable: teachers' sense of self-efficacy, and (c) criterion variable: student's achievement. Among 284 teachers who participated in this study, Sources of the SelfEfficacy Inventory (SOSI) and Teachers' Sense of Efficacy Scale (TSES) were distributed. Findings of this study indicated that between two suggested models, the dependent model showed the best overall fit to the data. In this model, teachers' self-efficacy had mediational role between sources of teachers' self-efficacy and student's achievement.
\end{abstract}

Keywords Sources of efficacy information - Teachers' self-efficacy beliefs - Student's achievement $\cdot$ SEM

\section{Introduction}

Efficacy beliefs affect the effort teachers invest in teaching, the goals they set, and their level of aspiration. Teachers

\section{F. S. Mohamadi ( $\square)$}

Department of Educational psychology, Saveh Branch,

Islamic Azad University, Saveh, Iran

e-mail: fshaterian@yahoo.com

H. Asadzadeh

Department of psychology and education, Allameh Tabataba'i

University, Tehran, Iran with a strong sense of efficacy tend to exhibit greater levels of planning and organization (Allinder 1994). They also are more open to new ideas and are more willing to experiment with new methods to better meet the needs of their students (Stein and Wang 1988).

Teachers' confidence in their ability to perform the actions that lead to student learning is one of the few individual characteristics that reliably predicts teacher practice and student outcomes (Woolfolk and Hoy 1990). A plethora of studies have related teachers' sense of efficacy to student achievement (Ashton and Webb 1986; Ross 1992), motivation (Midgley et al. 1989), and sense of efficacy (Anderson et al. 1988). Teachers' sense of efficacy has also been related to teacher behavior in the classroom (Ghaith and Yaghi 1997; Guskey 1988; Milner 2002), their ideology about the control of pupils (Woolfolk and Hoy 1990), enthusiasm for teaching (Allinder 1994), and quality of teaching (Raudenbush et al. 1992). Teachers with higher levels of self-efficacy were less critical of students when they made errors (Ashton and Webb 1986), and more willing to support and cope with students' emotional and behavioral difficulties (Poulou and Norwich 2002). These beliefs have a greater effect on the way prospective teachers organize their teaching acts than knowledge and are stronger indicators for predicting their teaching behavior (Pajares 1992). Current understandings of teacher efficacy underscore the multidimensionality and specificity of these beliefs (Tschannen-Moran et al. 1998). For example, the Tschannen-Moran and Woolfolk-Hoy (2001) measure of teacher efficacy (i.e., Teacher Sense of Efficacy Scale: TSES) identified three areas for which teachers may hold differing levels of efficacy: classroom management, instructional practices, and student engagement. These three dimensions of efficacy represent the richness of teachers' work lives and the requirements of good teaching. 
Social-cognitive theory provides some general guidance about possible sources of teachers' sense of efficacy. Bandura $(1986,1997)$ posited that self-efficacy beliefs are constructed based on four sources of efficacy information: mastery experiences, Vicarious experiences, Verbal or Social persuasion, and Emotional/Physiological states (Tschannen-Moran, et al. 1998). Goddard (2001) explains "Efficacy beliefs are developed through individual cognitive processing that uniquely weighs the influence of efficacy shaping information obtained through mastery experience, vicarious experience, social persuasion, and affective states".

\section{The hypothesized sources of self-efficacy}

Mastery Experiences: Mastery experiences are the most important sources of efficacy information according to Bandura (1986, 1997). Efficacy beliefs are raised if a teacher perceives her or his teaching performance to be a success, which then contributes to the expectations that future performances will likely be proficient (TschannenMoran and Woolfolk Hoy 2007). Bandura (1997) theorized that the most influential source of information comes from the interpreted results of past performance. These past performance accomplishments can create a strong sense of efficacy to accomplish similar tasks in the future. Alternatively, repeated failure can lower efficacy perceptions. Thus, teachers' sense of efficacy is affected by the positive or negative experiences.

Vicarious experiences: The second source of self-efficacy information is the vicarious experience gained by observing others performing tasks. By observing the successes and failures of others, people gather information that contributes to their judgments about their own capabilities. The degree to which the observer identifies with the model moderates the efficacy effect on the observer (Bandura 1997). The more closely the observer identifies with the model, the stronger will be impact on efficacy. When a credible model teaches well, the efficacy of observer is enhanced. When the model performs poorly, the efficacy expectation of the observer decreases (Woolfolk Hoy and Burke-Spero 2005)

Verbal or Social Persuasion: Types of social persuasion such as verbal feedback, encouragement, praise, norms of persistence, and achievement can induce a supportive social environment, whereas lack of feedback and criticism from colleagues and students can create an unsupportive environment (Milner and Hoy 2003). This source of efficacy information is the least effective for the long term although it might be effective in the short term. The potency of the persuasion depends on the credibility, trustworthiness, and expertise of the persuader (Bandura 1997). Verbal persuasion has to do with verbal interactions that a teacher receives about his or her performance and prospects for success from important others in the teaching context, such as administrators, colleagues, parents, and members of the community at large. For teachers, for example, the responses of their students could consist of a form of social persuasion (Mulholland and Wallace 2001).

Emotional/Physiological states: States or emotional/ physiological states are also sources of efficacy information. Powerful emotional arousal, such as anxiety, can effectively alter individuals' beliefs about their capabilities. People may view a state of arousal as an energizing factor that can contribute to a successful performance, or they may view arousal as completely disabling.

Thus, teachers construct their self-efficacy beliefs through the interpretation and integration of information from these four sources. The strength of the contribution made by each source varies depending on the domain in question and on the cognitive processing strategies of the individual. The manner in which the multiple sources of information are weighted and combined influences the resulting self-efficacy.

From sources of teacher self-efficacy to student's achievement

It is of both theoretical and practical importance to understand the sources of information that teachers utilize in making judgments about their sense of efficacy. We require additional research about sources of efficacy information, in order to better train and equip teachers for their complex tasks. Anderson and Betz (2001) also argued that little research has focused on the sources of self-efficacy, in contrast to the amount of research on correlates or outcomes of self-efficacy. Although many studies have been carried out about the relation of teacher to the student achievement, in most of these studies, the impact of teacher's self-efficacy belief sources on student achievement has been ignored.

In fact, the construct of teacher self-efficacy has been identified as an important factor in academic learning, but the relationship among sources of teacher self-efficacy and student's achievement has not been examined. The review of researches in this area (Banadura's theory in teacher self-efficacy) reveals that there is need to explore the relationship between these sources and student's learning. This study designed to investigate these relationships

Purpose of the study

In Bandura's theory, four sources of efficacy belief-shaping information are not taken into consideration sufficiently, and this part of theory has been examined less. The purpose of this study was to explore the causal relationships between sources of teacher self-efficacy, teacher self-efficacy beliefs and student achievement. In fact, this study 
sought to examine whether teacher self-efficacy beliefs predict student achievement and whether perceived performance mediates and moderates this relationship?

For achieving this aim, we used Structural Equation Modeling technique.

\section{Methods}

Participants

Participants in this study were 284 high school teachers from 18 schools of the Qom province (Iran). Among the teachers, $146(51.4 \%)$ were women and $138(48.6 \%)$ were men. The participants' teaching experience ranged from 1 to 29 years, with mean of 12.11 years for women and a mean of 12.56 for men.

Measures and translation procedure

\section{Sources of the self-efficacy inventory}

The Sources of the Self-Efficacy Inventory (SOSI; Henson 1999) is a 19-item Likert-type scale (' 1 ' definitely not true for me to ' 5 ' definitely true for me) that consists of four subscales. Four subscales were constructed based on the work of Bandura (1997). These subscales involved: mastery experience, vicarious experience, verbal persuasion, and emotional/physiological states.

The SOSI was translated into Persian and back-translated into English by two independent official translators. Comparison of the original and back-translated into English version shows that there is a minor change between the two forms.

\section{Analyses of the reliability and construct validity of the SOSI}

In the pilot study ( $N=267)$, we first examined the internal consistency of its items and subscales. Cronbach's alpha for four subscales was 0.795 (Mastery experience), 0.768 (Vicarious Experience), 0.730 (Verbal Persuasion), and 0.627 (Emotional/Physiological States. On the other hand, confirmatory factor analysis was used to examine the construct validity. Using CFA, three theoretical models of the SOSI were evaluated for this pilot study. A CFA procedure (using Lisrel 8.50; Jöreskog and Sörbom 2001) with maximum-likelihood estimation was conducted on each of the three theoretical models. One- and two-factor models were rejected by estimation of confirmatory factor analysis. Just one model (the four-factor model) building on the source of efficacy information of Bandura (1997) was found to fit the data. The fit indices for the 4-factor model for this group were as follows: $\chi^{2}(d f=138)=204.32$, $p<.001, \quad \chi^{2} / d f=1.48, \quad$ RMSEA $=0 \quad .043 \quad(90 \%$ $\mathrm{CI}=0.030-0.054), \mathrm{CFI}=0.96$, and SRMR $=0.046$.

\section{Teachers' Sense of Self-Efficacy Scale}

The TSE measure contained 12 items and three factors. For each factor, 4 questions have been designed. These factors are as the following: Efficacy for instructional strategies, Efficacy for student engagement, and Efficacy for classroom management. Participants completed a 5-point scale, ranging from 1 "Nothing", to 5 " A great deal" to rank their self-efficacy related to 12 teaching-related tasks. Moderate alpha coefficients provided evidence for the internal consistency of scores on the TSES [0.81 for student engagement, 0.86 for instructional strategies, 0.86 for classroom management and overall $=0.90$ (TschannenMoran and Woolfolk-Hoy 2001)]. The Teachers' Sense of Efficacy Scale was translated into the Persian language by the official translator. Then, a different translator conducted a back translation into English. Minor translation discrepancies were found and corrected.

\section{Analyses of the reliability and validity of the TSES}

In the pilot study $(N=267)$, we evaluated reliability and validity of Teachers' Sense of Self-Efficacy Scale (TSES). (Tschannen-Moran and Woolfolk-Hoy 2001).

\section{Reliability}

Cronbach's alpha was used to assess the reliability or the internal consistency of the instrument, using SPSS software. The Teachers' Sense of Efficacy Scale, TSES showed a good overall reliability for the total scale of alpha $=0.837$. The reliability coefficients of each subscale were strong: TSES-SE (student engagement) with an alpha 0.949, and TSES-CM (classroom management) with an alpha $=0.908$, and TSES-IS (instructional strategies) with an alpha $=0.893$. On all of the subscales, deleting items did not increase the subscale alpha.

\section{Convergent, discriminant validity, and susceptibility} to socially desirable responding

To examine discriminant validity, we calculate the correlation between Teachers' Sense of Self-Efficacy Scale and a measure of distinctly different construct (22-items Maslach Burnout Inventory (Maslach and Jackson 1981). The coefficients of internal consistency (Cronbach's alpha) for Iranian form were 0.90 (Emotional exhaustion), 0.79 (Depersonalization), and 0.71(Personal accomplishment) (Ahgar 2006). Also, in pilot study, for examining convergent 
validity, we calculated a series of correlations between TSES and the scores on self-esteem [10-items Rosenberg SelfEsteem Scale: Cronbach's alpha was as follows: In US, overall $=0.91$ (Sinclair et al. 2010) and in Iran, overall $=0.85$ (Ahadi 2009)], and locus of control scales (24items Levenson (1981)). The coefficients of internal consistency (Cronbach' s alpha) for Iranian form were 0.60 (internality), 0.63 (powerful others), and 0.70 (chance) (Farahani et al. 1996) (all of which are constructs similar to selfefficacy). The issue of social desirability was examined by correlating scores on the TSES with scores on the MarloweCrowne Social Desirability Scale. The present study used a 10-items Strahan and Gerbasi (1972) scale to measure SDRB (Manley et al. 2007). In Iran, Samari and Lalifaz (2005) found internal consistency coefficient for the MCSDS $(a=0.64)$. Table 1 presents these correlations.

A look at the Table 2 indicates that the majority of correlations between these constructs and TSES are not significant $(p>0.05)$. But some of them have significant Pearson coefficient. For example, self-esteem is significantly positively correlated with three subscales of TSES and TSES total scores. The results of calculating convergent validity indicated that teacher self-efficacy is moderately correlated with self-esteem, rather than other similar constructs (locus of control). The relative strength of this relationship shows that the Teacher Self-efficacy Scale behaves in a theoretically sound manner. In addition, two subscales of The Maslach Burnout Inventory are significantly negatively correlated with two subscales of TSES (TSES-SE and TSES-IS) and TSES total scores. The results of calculating discriminant validity indicated that teacher self-efficacy construct measured by 12 -items scale is different from other measured construct. As a result of

Table 1 Convergent and discriminant validity and susceptibility to social desirable responding

\begin{tabular}{lcccc}
\hline $\begin{array}{l}\text { TSES } \\
\text { Construct }\end{array}$ & TSES-SE & $\begin{array}{l}\text { TSES- } \\
\text { CM }\end{array}$ & $\begin{array}{l}\text { TSES- } \\
\text { IS }\end{array}$ & $\begin{array}{l}\text { TSES } \\
\text { total } \\
\text { score }\end{array}$ \\
\hline Self-esteem & $0.146^{*}$ & $0.119^{*}$ & $0.131^{*}$ & $0.198^{* *}$ \\
Internality & 0.073 & 0.008 & $0.146^{*}$ & 0.11 \\
Chance & 0.075 & 0.032 & 0.049 & 0.08 \\
Emotional exhaustion & $-0.181^{* *}$ & -0.088 & $-0.126^{*}$ & $-0.20^{* *}$ \\
Depersonalization & -0.071 & 0.026 & 0.028 & -0.014 \\
Personal & $-0.207^{* *}$ & -0.084 & $-0.150^{*}$ & $-0.224^{* *}$ \\
$\quad$ accomplishment & & & & \\
MCSDS score & 0.1 & 0.002 & 0.03 & 0.057 \\
\hline
\end{tabular}

TSES-SE student engagement, TSES-CM classroom management, TSES-IS instructional strategies and MCSDS Marlowe-Crowne social desirability scale

Listwise $N=267$

** Correlation is significant at the 0.01 level (2-tailed)

* Correlation is significant at the 0.05 level (2-tailed) this fact, discriminant validity of Teacher Self-efficacy Scale was confirmed. On the other hand, the nonsignificant correlations between this scale and social desirability scale indicate that the three-factor solution extracted from pilot study is absolutely free of SDRB.

Confirmatory factor analysis was used to examine the construct validity. Maximum-likelihood CFA using Lisrel 8.50 (Jöreskog and Sörbom 2001) was conducted to compare alternative theoretical models. Because the TSES is a relatively new measure, we considered whether the measure was better conceptualized as a one-factor or a three-factor construct (proposed by Tschannen-Moran and Woolfolk-Hoy (2001)). A three-factor model was a significant improvement over the one-factor model with $\chi^{2} / d f$ ratio 1.76 wherein a ratio $<3.0$ indicates a good fit, RMSEA $=0.056(90 \%$ $\mathrm{CI}=0.036-0.075)$, and CFI 0.98. The three-factor model (Tschannen-Moran and Woolfolk-Hoy 2001) was a more appropriate fit than the one-factor model.

\section{Academic achievement}

In Iran, students were assessed by a combination of continuous assessment in the form of in-class test, project and essays, and by a closed-book examination at the end of the semester. Academic achievement is a composite measure of aggregate continuously assessed mark and examination mark in individual subject. This semester score for each student ranges from 0 to 20, indicating his/her performance on that specific subject. In the present study, two classes (each class had as the average 32 students) were selected from a school. In each class, 9 subjects (Mathematics, Physics, Chemistry, Biology, English, Arabic, Literature, Religious and Sociality) were taken into consideration. Therefore, each teacher had a mean score for each of his/ her classes on specific subject. Finally, the mean of junior student's first semester scores of each teacher has been considered as student achievement.

\section{Results}

Descriptive statistics and correlation analysis

Descriptive statistics and correlations between variables are reported in Table 2. In the first step, we computed correlations between observed variables and school performance. In addition, means and standard deviations of all variables were estimated.

Testing between structural equation models

In second step, structural equation models using LISREL (Jöreskog and Sörbom 2001) were tested. In this study, two 
Table 2 Means, standard deviations, and bivariate correlations between variables, from the SEM

\begin{tabular}{|c|c|c|c|c|c|c|c|c|c|}
\hline Variable & Mean & SD & 1 & 2 & 3 & 4 & 5 & 6 & 7 \\
\hline 1. Mastery experience & 23.91 & 7.49 & & & & & & & \\
\hline 2. Vicarious experience & 14.45 & 6.78 & $.41 * *$ & & & & & & \\
\hline 3. Verbal persuasion & 14.36 & 4.7 & $.73 * *$ & $.48 * *$ & & & & & \\
\hline 4. Physiological state & 8.75 & 3.78 & -.04 & -.05 & -.004 & & & & \\
\hline 5. Student engagement & 14.44 & 2.4 & $.36^{* *}$ & $.20 * *$ & $.29 * *$ & $-.20 * *$ & & & \\
\hline 6. Classroom management & 15.47 & 2.16 & $.26^{* *}$ & $.21 * *$ & $.23 * *$ & -.11 & 0.06 & & \\
\hline 7. Instructional strategies & 14.93 & 1.9 & $.32 * *$ & $.18 * *$ & $.29 * *$ & $-.19 * *$ & $.13 *$ & $.35^{* *}$ & \\
\hline 8. Academic achievement & 15.38 & 1.32 & $.18 * *$ & $.15^{*}$ & .10 & 0.05 & $.33 * *$ & $.17 * *$ & 0.07 \\
\hline
\end{tabular}

$N=284 ; * p<.05 ; * * p<.01 ; * * * p<.001$

latent variables were estimated: the first, sources of efficacy information and the second, teachers' sense of self-efficacy. The first latent variable was measured by the following observed variables: mastery experience, vicarious experience, verbal persuasion, and emotional/physiological states. The other latent variable was measured by the following observed variables: student engagement, classroom management, and instructional strategies.

In model I, we tested an independent two-factor model. In this model, sources of efficacy information and teachers' sense of self-efficacy independently influenced student achievement. In model II, we examined a dependent twofactor model, consisting of: (a) antecedent variable, containing the sources of efficacy information, (b) mediator variable, containing teachers' sense of self-efficacy, influenced by sources of efficacy information, and (c) criterion variable, containing student's achievement which is predicted by the other variables in the model. In this relationship, sources of efficacy information directly influences teachers' sense of self-efficacy and indirectly influences student's achievement.

The fit indexes of two-independent-factor model show less good fit values when comparing with the two-dependent-factor model (see Table 3). For example, NFI was not very good, CFI is under 0.95 , and RMSEA is over 0.06 , only the S-RMR displays a good value. In comparison to the two-independent-factor model, the two-dependent-factor model (Teacher efficacy is moderator) shows somewhat better values. The analysis results reported show that twodependent-factor model fits the empirical data and all the fit indexes are good (Fig. 1).
Finally, we examined path diagram of a sources of efficacy information model without a direct effect on school performance. This diagram indicated that sources of efficacy information had a significant, positive impact on teachers' sense of self-efficacy, as hypothesized in Bandura theory. The indirect effect of the sources of efficacy information on student achievement via teacher self-efficacy was significant.

\section{Discussion}

The results of this study showed that the sources of efficacy information of teachers influence student's achievement. Teacher self-efficacy beliefs also mediate the effect of these sources on the student's achievement.

Since teacher's strong self-efficacy beliefs and high level of student's achievement are connected to each other, it is necessary to examine factors influencing the development of sense of efficacy among teachers. In this study, as Bandura (1997) hypothesized, mastery experience was found to be a powerful source of self-efficacy beliefs among the teachers. The findings of the study support previous studies demonstrating the strong effect of mastery experience on teacher self-efficacy beliefs. This finding echoes Bandura's and other researchers' (Pajares 1997; Mulholland and Wallace 2001; Palmer 2006) assertions that performance is a particularly important source of information. The findings of this study revealed that the influence of verbal persuasion source on teacher selfefficacy beliefs was greater than vicarious experience

Table 3 Fit indexes for two models of the antecedents of students' academic achievement

\begin{tabular}{llllllll}
\hline Model & $\chi^{2}$ & $\chi^{2} / d f$ & GFI & CFI & NFI & SRMR & RMSEA \\
\hline Independent two-factor model & 43.93 & 2.44 & 0.96 & 0.93 & 0.89 & 0.056 & 0.071 \\
Dependent two-factor model (TSES is moderator) & 37.96 & 2.23 & 0.97 & 0.95 & 0.91 & 0.057 & 0.066 \\
\hline
\end{tabular}

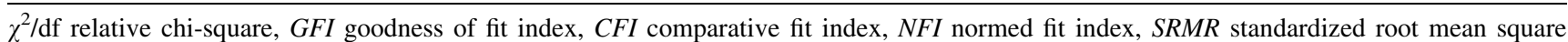
residual, RMSEA root mean squared error of approximation 
Fig. 1 A structural equation model of the effects of sources of efficacy information and Teachers' Sense of SelfEfficacy on academic achievement. Dashed lines indicate non-significant path coefficients

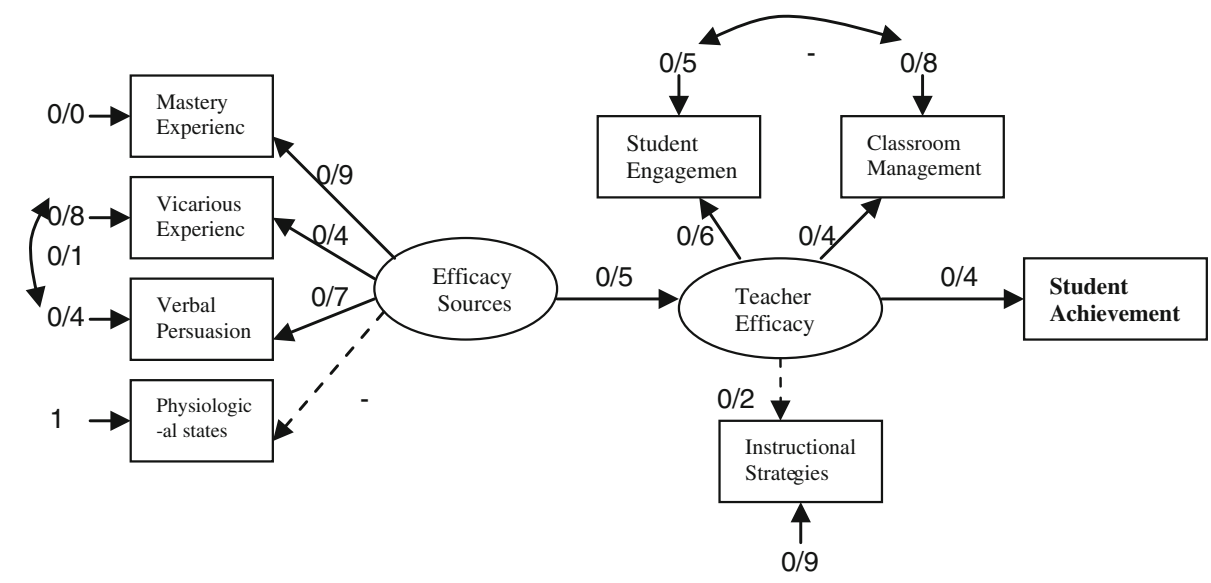

source. This result was inconsistent with the previous studies. Previous researchers believe that this source of efficacy information is the least effective for the long term. It appears Iranian people are more sensitive to others evaluations. We found that the feedback received from administrators, colleagues, parents, and even students was perceived as a powerful source for teacher self-efficacy beliefs, in agreement with Yeung and Watkins' (2000) work. Vicarious experiences did not receive high rating as potential sources of self-efficacy beliefs in teachers of Iran. Anderson and Betz (2001) arrived at similar results. Unfortunately, the modeling of teaching seemed restricted to high school and university context (Mulholland and Wallace 2001). Modeling has the greatest influence when the observed models are perceived to be similar to the observer and in situations in which the observer has little personal experience. Finally, the results also indicated that all of Bandura's sources of self-efficacy are not significant in this study. Physiological states (i.e., coping with stress, fear, and anxiety) cannot be assumed as a source of selfefficacy. This suggests that mastery experience may play a role in reducing negative visceral Arousal. This is in agreement with the view of Bandura (1997) who stated that anxiety could be diminished by modeling or mastery experiences (Palmer 2006). This result was in congruence with Bandura's theory and Mulholland and Wallace's (2001) research that stated affective and physiological states do not appear as important as other sources of teaching efficacy.

This study indicated that mastery experience, vicarious experience and verbal persuasion are effective factors that strengthen and increase teacher's self-efficacy beliefs. Among these 3 factors, achieving mastery experience in teaching seems to be the most important factors.

The relationship between teachers' sense of efficacy and student outcome is very important and should be taken into serious consideration. To enhance teachers' sense of efficacy means to enhance their belief in their educability of all students, even those in challenging circumstances. Thus, it seems necessary to increase these beliefs among teachers to help students overcome academic problem and high levels of success. Also, much more attention needs to be paid to the programs that increase efficacy beliefs of teachers.

In addition, this study was the first attempt to employ the Teachers' Sense of Efficacy Scale (TSES) with Iranian teachers. Since vast majority of information in teacher's self-efficacy field belongs to North American researchers and there is not sufficient information and knowledge in this field in Asian countries, conducting independent researches in this area outside of North America cultural context seems to be necessary.

Finally, we believe these relationships merit additional empirical attention, both through quantitative and qualitative methodological approaches. In addition, researchers should seek to determine how these relationships might vary by other individual-level or school-level characteristics or as a function of the interactions of contextual variables.

Open Access This article is distributed under the terms of the Creative Commons Attribution Noncommercial License which permits any noncommercial use, distribution, and reproduction in any medium, provided the original author(s) and source are credited.

\section{References}

Ahadi, B. (2009). Relationship of loneliness and self-esteem with attachment style in college student. Psychological Studies, 5(1), 95-112.

Ahgar, Gh. (2006). The role of the school organizational culture on burnout of teacher in middle-school at Tehran city. Education seasonal, 22(2), 93-123.

Allinder, R. M. (1994). The relationship between efficacy and the instructional practices of special education teachers and consultants. Teacher Education and Special Education, 17, 86-95.

Anderson, R., Greene, M., \& Loewen, P. (1988). Relationships among teachers' and students' thinking skills, sense of efficacy, and student achievement. Alberta Journal of Educational Research, 34(2), 148-165.

Anderson, S., \& Betz, N. (2001). Sources of social self-efficacy expectations: Their measurement and relation to career development. Journal of Vocational Behavior, 58, 98-117. 
Ashton, P. T., \& Webb, R. B. (1986). Making a difference: teachers' sense of efficacy and student achievement. New York: Longman.

Bandura, A. (1986). Social foundations of thought and action: a social cognitive theory. Englewood Cliffs, NJ: Prentice Hall.

Bandura, A. (1997). Self-efficacy: the exercise of control. New York: Freeman \& Company.

Farahani, M. N., Cooper, M., \& Jin, P. (1996). Is Locus of control unidirectional or multidimensional? Data from Persian translation of Rotter's I-E Scale and Levenson's I, P, and C Scales. Psychology Research, 3(4), 30-42.

Ghaith, G., \& Yaghi, H. (1997). Relationships among experience, teacher efficacy and attitudes towards the implementation of instructional innovation. Teaching and Teacher Education, 14, 451-458.

Goddard, R. D. (2001). Collective efficacy: A neglected construct in the study of schools and student achievement. Journal of Educational Psychology, 93(3), 467-476.

Guskey, T. (1988). Teacher efficacy, self-concept and attitudes toward the implementation of instructional innovation. Teaching and Teacher Education, 4, 63-69.

Henson, R. K. (1999). The sources of self-efficacy inventory. Unpublished instrument. Huttiesburg, MS: University of Southern Mississippi.

Jöreskog, K., \& Sörbom, D. (2001). LISREL 8.5: Analysis of linear structural relationships by the method of maximum likelihood. Chicago: Scientific Software International.

Levenson, H. (1981). Differentiating among internality, powerful others and chance. In H. M. Lefcourt (Ed.), Research with the locus of control construct (Vol. 1, pp. 15-63). New York: Academic Press

Maslach, C., \& Jackson, S. E. (1981). The measurement of experienced burnout. Journal of Occupational Behavior, 2, 99-113.

Midgley, C., Feldlaufer, H., \& Eccles, J. (1989). Change in teacher efficacy and student self- and task-related beliefs in mathematics during the transition to junior high school. Journal of Educational Psychology, 81, 247-258.

Milner, H. (2002). A case study of an experienced teacher's selfefficacy and persistence through crisis situations: Theoretical and practical considerations. High School Journal, 86, 28-35.

Milner, H., \& Hoy, A. (2003). A case study of an African American teacher's self-efficacy, stereotype threat and persistence. Teaching and Teacher Education, 19, 263-276.

Manley, G. G., Benavidez, J., \& Dunn, K. (2007). Development of a personality biodata measure to predict ethical decision making. Journal of Managerial Psychology, 22(7), 664-682.

Mulholland, J., \& Wallace, J. (2001). Teacher induction and elementary science teaching: Enhancing self-efficacy. Teaching and Teacher Education, 17, 243-261.

Pajares, M. F. (1992). Teachers' beliefs and educational research: Cleaning up a messy construct. Review of Educational Research, 62(3), 307-332.
Pajares, M. F. (1997). Current directions in self-efficacy research. In M. Maehr \& P. Pintrich (Eds.), Advances in motivation and achievement. London: JAI Press.

Palmer, D. H. (2006). Sources of self-efficacy in a science methods course for primary teacher education students. Research in Science Education, 36, 337-353.

Poulou, M., \& Norwich, B. (2002). Teachers' cognitive, affective and behavioral responses to children with emotional and behavioral difficulties: A model of decision making. British Educational Research Journal, 28(1), 111-138.

Raudenbush, S., Bhumirat, C., \& Kamali, M. (1992). Predictors and consequences of primary teachers' sense of efficacy and students' perceptions of teaching quality in Thailand. International Journal of Educational Research, 17(2), 165-177.

Ross, J. A. (1992). Teacher efficacy and the effect of coaching on student achievement. Canadian Journal of Education, 17(1), $51-65$.

Samari, A. A., \& Lalifaz, A. (2005). Effect of life skills training program on family stress and social desirability. The Quarterly Journal of Fundamentals of Mental Health, 7(25 \& 26), 47-55.

Sinclair, S. J., Blais, M. A., Gansler, D. A., Sandberg, E., Bistis, K., \& LoCicero, A. (2010). Psychometric properties of the rosenberg self-esteem scale: Overall and across demographic groups living within the United States. Evaluation \& the Health Professions, 33(1), 56-80.

Stein, M. K., \& Wang, M. C. (1988). Teacher development and school improvement: The process of teacher change. Teaching and Teacher Education, 4, 171-187.

Strahan, R., \& Gerbasi, K. C. (1972). Short, homogeneous versions of the Marlowe-Crowne Social Desirability Scale. Journal of Clinical Psychology, 28, 191-193.

Tschannen-Moran, M., Woolfolk-Hoy, A., \& Hoy, W. K. (1998). Teacher efficacy: Its meaning and measure. Review of Educational Research, 68(2), 202-248.

Tschannen-Moran, M., \& Woolfolk-Hoy, A. (2001). Teacher efficacy: Capturing an elusive construct. Teaching and Teacher Education, 17(7), 783-805.

Tschannen-Moran, M., \& Woolfolk Hoy, A. (2007). The differential antecedents of self-efficacy beliefs of novice and experienced teachers. Teaching and Teacher Education, 23, 944-956.

Woolfolk Hoy, A., \& Burke-Spero, R. (2005). Changes in teacher efficacy during the early years of teaching: A comparison of four measures. Teaching and Teacher Education, 21, 343-356.

Woolfolk, A., \& Hoy, W. (1990). Prospective teachers' sense of efficacy and beliefs about control. Journal of Educational Psychology, 82, 81-91.

Yeung, K., \& Watkins, D. (2000). Hong Kong student teachers' personal construction of teaching efficacy. Educational Psychology, 20(2), 213-235. 